\title{
Gamma Knife Radiosurgery on the Trigeminal Root Entry Zone for Idiopathic Trigeminal Neuralgia: Results and a Review of the Literature
}

\author{
So Hee Park and Jin Woo Chang \\ Department of Neurosurgery, Yonsei University College of Medicine, Seoul, Korea.
}

\begin{abstract}
Trigeminal neuralgia (TN) is a chronic disorder of the trigeminal nerve characterized by repeated electrical shock-like sensations on one side of the face. It can cause severe pain in the face and disrupt or impair quality of life in patients. Options for the management of TN consist of pharmacological and surgical treatments, including Gamma Knife radiosurgery (GKRS). GKRS has been used for TN for a long time because of its low rate of complications and high success rate. Moreover, GKRS can be of use for drugresistant TN patients who are poor surgical candidates due to medical comorbidities, patients of older age, or patients who refuse invasive therapy. We reviewed the rationale, effects, safety, and current treatment policies of GKRS for TN in view of our institution's results and a review of the literature to date.
\end{abstract}

Key Words: Gamma Knife radiosurgery, trigeminal neuralgia, facial pain

\section{INTRODUCTION}

Trigeminal neuralgia (TN) is defined by the International Headache Society as "recurrent unilateral brief electric shock-like pains, abrupt in onset and termination, limited to the distribution of one or more divisions of the trigeminal nerve and triggered by innocuous stimuli." ${ }^{1}$ It is characterized by the presence of a trigger zone, no objective neurological deficit, and no other identified causes of facial pain; it can cause severe pain and disrupt or impair quality of life in patients. ${ }^{2}$

Treatments for TN consist of pharmacological treatments, such as that with carbamazepine; surgical treatments, including open surgery and percutaneous procedures; and radiosurgery, including gamma knife radiosurgery (GKRS). Historical-

\footnotetext{
Received: November 11, 2019 Revised: December 24, 2019

Accepted: December 30, 2019

Corresponding author: Jin Woo Chang, MD, PhD, Department of Neurosurgery, Yonsei University College of Medicine, 50-1 Yonsei-ro, Seodaemun-gu, Seoul 03722, Korea.

Tel: 82-2-2228-2150, Fax: 82-2-393-9979, E-mail: jchang@yuhs.ac

-The authors have no potential conflicts of interest to disclose
}

(C) Copyright: Yonsei University College of Medicine 2020

This is an Open Access article distributed under the terms of the Creative Commons Attribution Non-Commercial License (https://creativecommons.org/licenses/ by-nc/4.0) which permits unrestricted non-commercial use, distribution, and reproduction in any medium, provided the original work is properly cited. ly, GKRS was introduced as a treatment for TN. The Swedish neurosurgeon Lars Leksell began treating TN patients in 1951 using a prototype guiding device linked to a dental X-ray machine. ${ }^{3}$ Lindquist reported on the progress of TN patients who had undergone GKRS in 1991, and several studies have documented the safety and efficacy of GKRS, including long-term results, for TN..$^{4-6}$ Other techniques of radiosurgery, such as cyber knife surgery and linear accelerator, were introduced in the 2000s and have shown effectiveness, compared to other surgical treatments. ${ }^{7,8}$

Several modifications have been made to the treatment regimens for GKRS over the past few decades. We reviewed the rationale, effects, safety, and current treatment policies of GKRS for TN in view of our institution's results and a review of the literature to date.

\section{PATHOPHYSIOLOGY OF TN}

The pathogenesis of TN is not fully understood, and its exact pathophysiology remains controversial. However, in general, it is described by a mixed peripheral and central mechanism. ${ }^{9}$ Neurovascular conflict is the most accepted theory, as it is related to TN in a vast majority of cases. ${ }^{10}$ Chronic nerve compression results in demyelination of trigeminal sensory fibers within the 
proximal nerve root, with progressive axonal degeneration. ${ }^{11}$ Demyelination can lead to ephaptic transmission, and the reentry mechanism causes an amplification of sensory inputs..$^{10,12}$ Meanwhile, nerve injury leads to a release of mediators that sensitize peripheral nerve terminations, resulting in neurochemical and phenotypic changes and increased excitability of trigeminal neurons and trigeminal nuclei (central sensitization). ${ }^{11}$ Ultrastructural and biochemical changes in axons and myelin are seen in the root, the Gasserian ganglion, or both. ${ }^{13}$

\section{CLINICAL FEATURES AND CLASSIFICATION}

According to the International Classification of Headache Disorders, 3rd edition (ICHD-3), TN can be diagnosed when recurrent paroxysms of unilateral facial pain of a severely intense, electric shock-like, shooting, stabbing, or sharp nature occurs in one or more divisions of the trigeminal nerve. ${ }^{1}$ It should not radiate beyond the territory of the trigeminal nerve, should last between 1 second and 2 minutes, and should be precipitated by innocuous stimuli within the affected trigeminal distribution. TN is divided into the following three categories according to its cause: classical TN, secondary TN, and idiopathic TN. Classical TN refers to cases without an apparent cause other than neurovascular compression. When underlying diseases are present, such as a tumor in the cerebellopontine angle, arteriovenous malformation, or multiple sclerosis, secondary TN is diagnosed. Idiopathic TN could be diagnosed in cases where neither an electrophysiological test nor magnetic resonance images show significant abnormalities. Besides the ICHD classification, the Burchiel classification is also used to categorize TN and related facial pain syndromes using the characteristics of pain. ${ }^{14}$ The classification is based on the patient's history and is shown in Table 1.

\section{GKRS AS A TREATMENT METHOD}

\section{Treatment method for $\mathrm{TN}$}

Treatments for TN are divided into the following three categories: pharmacological treatments; surgical treatments, including microvascular decompression (MVD) and percutaneous procedures, such as radiofrequency rhizotomy (RFR), balloon microcompression, and glycerol injection; and stereotactic radiosurgery.

The first therapeutic line is pharmacological treatment with carbamazepine. It is the only drug shown in a random-controlled trial to reduce the intensity and frequency of attacks, and it provides significant pain control in $80-85 \%$ of patients. ${ }^{15}$ Nevertheless, its efficacy can decrease, and in the long term, many patients become drug-resistant. ${ }^{16}$ Oxcarbazepine, baclofen, lamotrigine, and pimozide can also be used..$^{17}$
Table 1. Burchiel Classification of TN and Related Facial Pain Syndromes

\begin{tabular}{ll}
\hline \multicolumn{1}{c}{ Burchiel classification } & \multicolumn{1}{c}{ History } \\
\hline Spontaneous onset & $>50 \%$ episodic pain, sharp, shooting, \\
TN, Type 1 & $\begin{array}{c}>50 \% \text { constant pain, aching, throbbing, } \\
\text { burning }\end{array}$ \\
TN, Type 2 & \\
Trigeminal injury & Unintentional, incidental trauma \\
\hline Trigeminal neuropathic pain & Intentional deafferentation \\
\hline Trigeminal deafferentation pain & Multiple sclerosis \\
Symptomatic TN & Trigeminal Herpes zoster outbreak \\
Postherpetic neuralgia & Somatoform pain disorder \\
Atypical facial pain &
\end{tabular}

TN, trigeminal neuralgia.

Surgical treatment is the second therapeutic line and includes open surgery, percutaneous surgery, and radiosurgery. It is used in patients with medically intractable pain or those who suffer from side effects related to medication. MVD alleviates the underlying cause of a compressed trigeminal nerve root through exploration of the posterior fossa. It is considered a reference treatment modality, as it provides pain relief for approximately $90 \%$ of patients and has long-term effects (68-88\% after 5 years and $61-88 \%$ after 10 years). ${ }^{18,19}$ Therefore, MVD should be considered as the first surgical treatment modality for young patients with an obvious neurovascular conflict. ${ }^{20}$ However, major complications of surgery can include hearing loss, cerebrospinal fluid leakage, infection, hemorrhage, and brainstem infarction. ${ }^{18,21}$

Percutaneous procedures are ablative techniques performed at the level of the Gasserian ganglion and are mechanistically based on physical, thermic, and chemical actions. Percutaneous procedures show a high initial success rate; however, over time, the recurrence rate is higher than that of MVD. ${ }^{22}$ The initial success rate for balloon microcompression was reported at $82-99 \%$, and the median pain-free time was 20 months. ${ }^{23,24}$ For glycerol injection, the initial success rate and the median pain-free time were $73-96 \%$ and 21 months, respectively. ${ }^{24,25}$ For RFR, the initial success rate was $78.8-100 \%$, and the probabilities of remaining pain-free 1,2 , and 11 years after the procedure were $65 \%, 49 \%$, and $26 \%$, respectively. ${ }^{26-28}$ These ablative procedures pose a risk of hypesthesia, dysesthesia, severe facial numbness, corneal keratitis, and masseter muscle weakness. ${ }^{29,30}$

Lastly, GKRS can be used for drug-resistant TN patients who are poor surgical candidates due to medical comorbidities or age or for those who refuse invasive therapy, especially in the absence of other primary indications, such as neurovascular conflict. GKRS has a very high rate of pain relief with minimal complications, showing a gradual decline in the complication rate due to advancement in imaging modalities. ${ }^{22}$ Burchiel's type 1 and type $2 \mathrm{TN}$ are the most common indications of GKRS. GKRS may also be used in selected cases of multiple sclerosisrelated and post-herpetic $\mathrm{TN}$ and in some cases of atypical fa- 
cial pain..$^{31,32}$

\section{Institutional results on GKRS for TN}

A total of 235 patients underwent GKRS for TN between February 1996 and September 2018. The indications for GKRS included failure of pharmacological treatment, significant adverse effects from medication, and failure of prior surgical treatment. Of these patients, 157 had charts and a follow-up period of more than 1 year. Of these patients, except for those with TN related to tumors and multiple sclerosis, 142 patients were reviewed (Fig. 1). Patient characteristics are shown in Table 2. GKRS was performed with a Gamma Knife (Leksell Gamma Knife, Elekta Instruments, Atlanta, GA, USA). Seven patients were treated with the Gamma Knife Model B, 28 patients with the Gamma Knife Model C, and 107 patients with the Perfexion Gamma Knife.

GKRS treatment was planned using T2-weighted magnetic resonance images with a slice thickness of $1 \mathrm{~mm}$ and constructive interference in steady-state images with 0.5 - $\mathrm{mm}$ axial slic-

TN treated with GKRS

from Feb 1996 to Sep 2018, n=235

Excluded unidentifiable charts, $n=25$

Excluded at follow-up period (less than 1 year), $n=53$

Excluded TN related to tumor and MS, n=15

Included patients, $\mathrm{n}=142$

Fig. 1. Flow chart for patient inclusion. TN, trigeminal neuralgia; GKRS, Gamma Knife radiosurgery; MS, multiple sclerosis.

Table 2. Clinical Characteristics of Patients

\begin{tabular}{lc}
\hline \multicolumn{1}{c}{ Variables } & Value \\
\hline Age & $68.58 \pm 11.33$ \\
Sex (\%) & \\
Male & $46(32.39)$ \\
\hline Female & $97(67.61)$ \\
Prior procedure (\%) & \\
\hline MVD & $8(5.63)$ \\
\hline RFR & $11(7.75)$ \\
\hline Radiosurgery & $4(2.82)$ \\
\hline Others & $14(9.86)$ \\
\hline None & $105(73.94)$ \\
Trigeminal division effected (\%) & \\
\hline V1 & $7(4.93)$ \\
\hline V2 & $25(17.61)$ \\
\hline V3 & $44(30.99)$ \\
\hline V1, 2 & $25(17.61)$ \\
\hline V2, 3 & $30(21.13)$ \\
\hline V1, 2, 3 & $11(7.75)$ \\
\hline
\end{tabular}

MVD, microvascular decompression; RFR, radiofrequency rhizotomy. es obtained with the stereotactic frame fixed to the head under local anesthesia. A single 4-mm isocenter with two or three beam blocking was used for treatment. It was positioned to cover the trigeminal root entry zone (REZ). After February 2005, planning was done such that a 15-Gy isodose line invaded less than $5 \%$ of the brainstem. The dose used varied from 60 to $90 \mathrm{~Gy}$.

Pain from TN was assessed using Barrow Neurologic Institute (BNI) pain scores. BNI scores of I-IIIb were considered as indicative of successful treatment, whereas BNI pain scores of IV and $\mathrm{V}$ were considered reflective of unsuccessful treatment. Following improvements in pain after GKRS, any worsening of the pain (even if the level of pain was milder than that present prior to treatment) was considered as recurrence.

The median follow-up period was 37 months (12-250 months, $54.35 \pm 49.51$ months). The median dose of gamma rays was 85 Gy (60-90 Gy, 84.23 \pm 3.743 Gy). After GKRS, $93.7 \%$ of patients (133/142) experienced successful treatment (Fig. 2). Of these, recurrence of pain occurred in 50 patients $(37.6 \%, 50 / 133)$, and the median time to recurrence was 29 months (2-166 months, $42.26 \pm 38.08$ months). Among patients who experienced recurrence, six $(12 \%, 6 / 50)$ needed additional surgery or procedures, and the rest were controlled by medication. Complications were reported in a total of 25 patients $(17.6 \%, 25 / 142)$ and included facial hypesthesia in 19 patients $(13.4 \%)$, dysesthesia in 2 patients (1.4\%), and dry eye syndrome in 4 patients (2.8\%) (Table $3)$. Univariate comparisons were performed using the independent t-test and one-way ANOVA test. There were no statistically significant correlations between the prior procedure and complications ( $p=0.068$ ) or between the types of prior procedures and complications ( $p=0.705)$. There were also no statistically significant relationships between dose and successful treatment, recurrence, and complications under significance of $p<0.05$.

\section{Pain relief after GKRS}

The rationale for achieving pain relief after GKRS is related to focal axonal degeneration of the trigeminal nerve associated

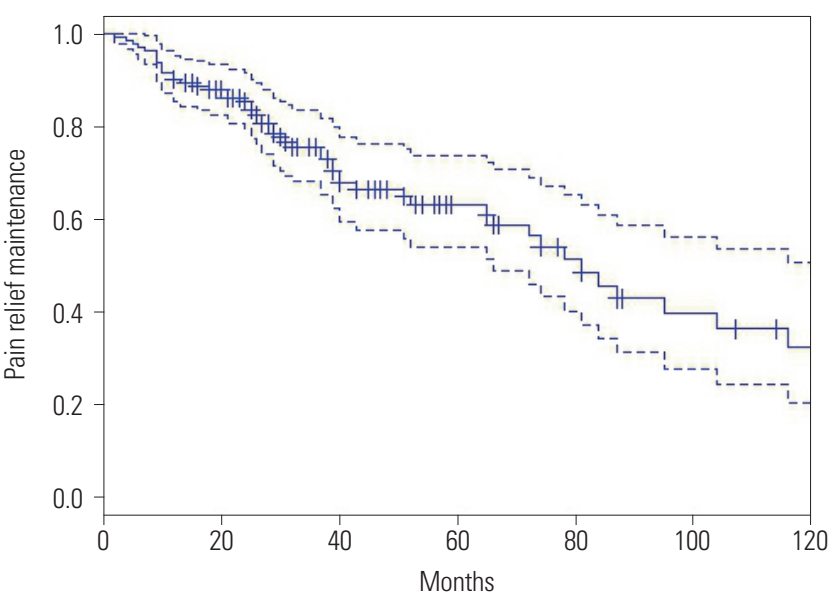

Fig. 2. Predicted pain relief maintenance period after Gamma Knife radiosurgery. Solid line represents predicted pain relief maintenance period and dotted line represents $95 \%$ confidence interval. 
with nociceptive sensibility, destruction of ionic channels, and electrophysiological blocking initially after nerve irradiation. ${ }^{33,34}$ Additionally, a delayed radiation effect with axonal degeneration has been proposed, as some patients experience a late response after GKRS. ${ }^{35}$ In the literature, the latency to pain relief was 15 to 78 days on average, and the maximum time to pain relief was 6 months after treatment. ${ }^{29}$

Table 4 lists studies with more than 100 patients who underwent GKRS for TN (Fig. 3). GKRS showed high rates of pain relief, ranging from $70-98 \%$ in large studies of over 100 patients (Fig. 4). Pain control was achieved in $69-85 \%$ of cases at 1 year, $59 \%$ at 2 years, and $38-52 \%$ at 5 years. ${ }^{35,36}$ Regarding long-term results, rates of pain control maintenance were $32-59.7 \%$ at 7 years and $30-45.3 \%$ at 10 years. ${ }^{5,6,37}$ Although follow-up periods vary among the studies, making direct comparison difficult, the average pain free duration was 7-58 months. ${ }^{35,38,39}$ The mean recurrence rate was $26.9 \%$, with a range of $3.3-45.1 \%$ (Fig. 5). In comparison, our data showed a higher recurrence rate than

Table 3. Results of Gamma Knife Radiosurgery for Trigeminal Neuralgia

\begin{tabular}{lc}
\hline \multicolumn{1}{c}{ Treatment outcome } & Number of patients (\%) \\
\hline Treatment failure (BNI pain score IV, V) & $9(6.3)$ \\
Treatment success (BNI pain score I-IIIb) & $133(93.7)$ \\
Recurrence & $50(37.6)$ \\
Complication & $25(17.6)$ \\
Hypesthesia & $19(13.4)$ \\
Dysesthesia & $2(1.4)$ \\
Dry eye syndrome & $4(2.8)$ \\
\hline
\end{tabular}

BNI, Barrow Neurological Institute. the average. This may be due to a difference in follow-up periods, because in our study, some patients experienced recurrent pain after approximately 14 years.

\section{Complications of GKRS}

Complications due to GKRS are uncommon, with hypesthesia being the most common adverse event. The incidence of hypesthesia is reported to be up to $2.7-55.0 \%$, with a mean occurrence rate of $22.55 \%$, slightly higher than our result (Table 4). Similar to the latency period for GKRS to be effective, there may also be a latency period between the procedure and the development of complications. The mean time to hypesthesia occurrence ranged from 6 to 36 months. ${ }^{29}$

Other complications include dysesthesia, deafferentation pain, dysgeusia, dry eye syndrome, keratitis, hearing impairment, and masticator weakness. ${ }^{41,42}$ Rarely, significant injury to

A systemic review of English-language literature using PubMed database

- Searching terms, "Trigeminal neuralgia" and "Gamma Knife" in screening of titles and/or abstracts

- Until September 2019

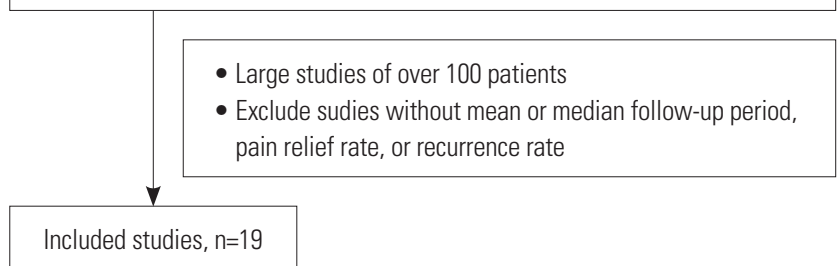

Fig. 3. Flow chart for inclusion of studies analyzing pain relief, complication, and recurrence rates.

Table 4. Review of Studies with more than 100 Cases of Gamma Knife Radiosurgery for Trigeminal Neuralgia

\begin{tabular}{|c|c|c|c|c|c|}
\hline Study (year) & Number of patients & $\begin{array}{c}\text { Mean or median follow-up } \\
\text { period (months) }\end{array}$ & Pain relief (\%) & Complications (\%) & Recurrence (\%) \\
\hline Young, et al. (1998) ${ }^{66}$ & 110 & 19.8 & 95.5 & 2.7 & 3.3 \\
\hline Maesawa, et al. $(2001)^{35}$ & 220 & 22 & 78.6 & 10.2 & 13.6 \\
\hline Pollock, et al. $(2002)^{42}$ & 117 & 26 & 75 & 37 & 16 \\
\hline Petit, et al. $(2003)^{67}$ & 112 & 30 & 77 & 7.3 & 29 \\
\hline Sheehan, et al. $(2005)^{68}$ & 136 & 19 & 70 & 19 & 24 \\
\hline Urgosik, et al. $(2005)^{38}$ & 107 & 60 & 96 & 20 & 25 \\
\hline Longhi, et al. $(2007)^{40}$ & 170 & 37.4 & 90 & 8.75 & 18 \\
\hline Fountas, et al. $(2007)^{48}$ & 106 & 34.3 & 89.6 & 16 & 32.1 \\
\hline Kondziolka, et al. $(2010)^{5}$ & 503 & 24 & 89 & 10.5 & 42.9 \\
\hline Hayashi, et al. $(2011)^{69}$ & 130 & 38 & 98 & 24 & 18.0 \\
\hline Marshall, et al. $(2012)^{44}$ & 448 & 20.9 & 86 & 44 & 40 \\
\hline Young, et al. $(2013)^{47}$ & 315 & 68.9 & 85.6 & 32.9 & 14.3 \\
\hline Lucas, et al. $(2014)^{70}$ & 446 & 21.2 & 84.5 & 42 & 45.1 \\
\hline Régis, et al. $(2016)^{6}$ & 497 & 43.8 & 91.75 & 21.1 & 34.4 \\
\hline Taich, et al. $(2016)^{49}$ & 263 & 24 & 79 & NA & 39.8 \\
\hline Martínez Moreno, et al. (2016) & 117 & 66 & 91 & 32.5 & 19 \\
\hline Zhao, et al. $(2018)^{50}$ & 247 & 49.7 & 87.9 & 31.9 & 3.6 \\
\hline Gagliardi, et al. $(2018)^{72}$ & 166 & 64.7 & 78 & 24 & 31.2 \\
\hline Lee, et al. $(2018)^{73}$ & 108 & 17 & 80 & 55 & 22 \\
\hline
\end{tabular}




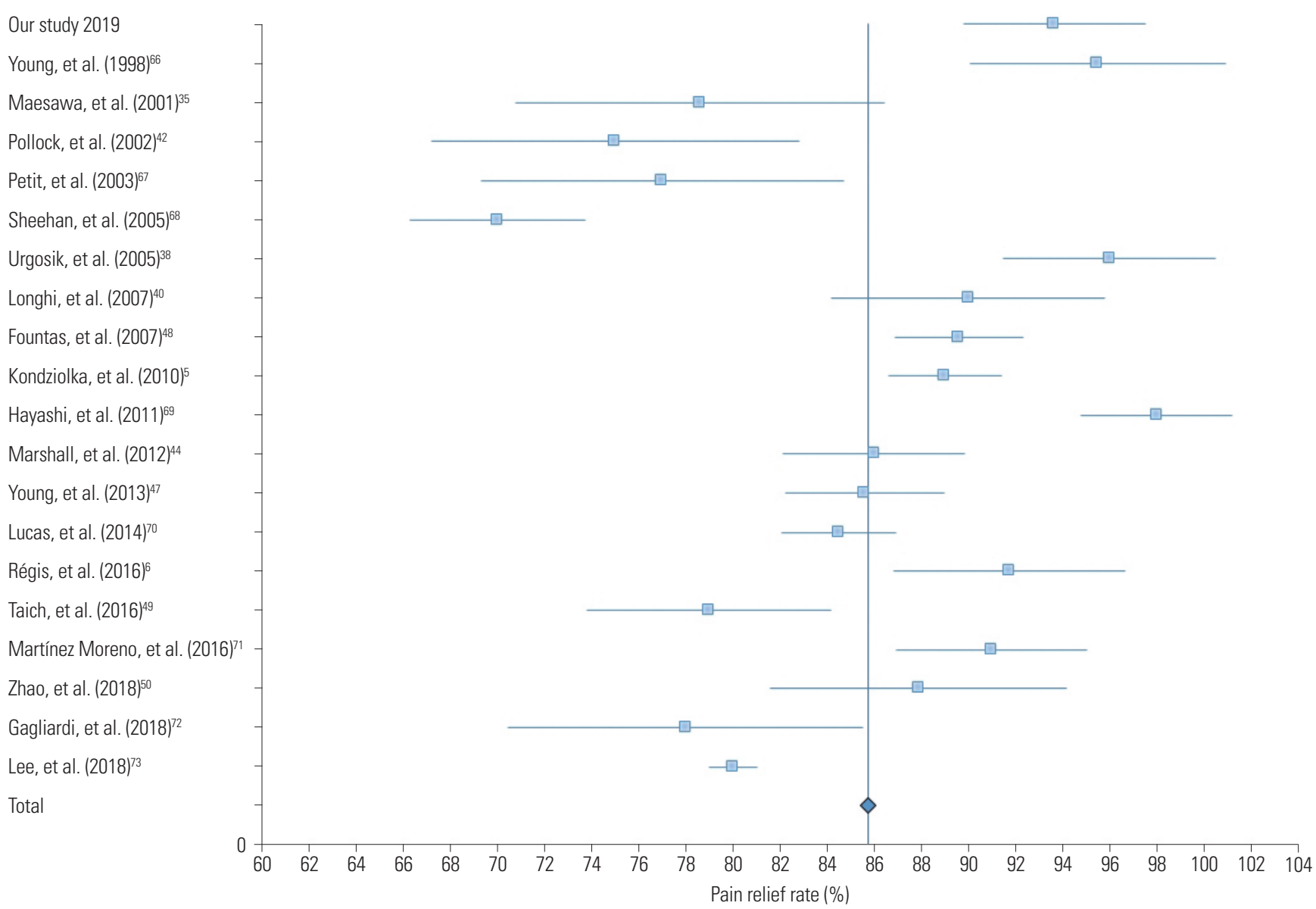

Fig. 4. Forest plot of pain relief rates in 19 studies. Confidence intervals were calculated at a confidence level of $95 \%$ for a single proportion.

adjacent vasculature due to high doses have been reported. ${ }^{43}$ Terms used in each article related to complications had a lack of precision; hence, there may be differences in the rate of complications. Studies have reported dysesthesia in 0-16\%, paresthesia in $0-13 \%$, deafferentation pain in $0-3.3 \%$, dry eye syndrome in $0-22.4 \%$, and keratitis in $0-7 \% .^{44-47}$

Complications were not associated with the prior procedure in previous studies, which is consistent with our results. ${ }^{48-50}$ This may be due to some differences in the mechanisms of complications in destructive procedures, such as GKRS, versus nondestructive procedures, such as MVD. Also, in MVD and other destructive procedures, such as RFR, the duration of complications is short, which does not seem to affect complications in a subsequent surgery. However, in the case of radiosurgery, there is a report that previous radiosurgery affects complications because there is a latency period of radiosurgery. ${ }^{49}$

Several studies have shown that complication rates are associated with the target selection, the length of the irradiated nerve, and the dose. ${ }^{42,51,52}$ Our study showed a complication rate similar to that in previous studies, and complications due to GKRS do not appear to be statistically related to the high dose used.

\section{Repeat GKRS}

Due to the low incidence of complications associated with GKRS, rather than other procedures, repeat GKRS may be considered for pain recurrence. Repeat GKRS appears to have a similar efficacy to initial GKRS for TN, with rates of complete and partial pain relief ranging from $78 \%$ to $85 \% .^{51,53,54}$ There is a report that prior GKRS is associated with bothersome facial numbness after GKRS. The main complications after repeat GKRS are new facial sensory symptoms caused by partial trigeminal nerve injury, seen in $11-69 \%$ of patients. ${ }^{54-56}$

Therefore, to reduce complications due to repeat GKRS, decreasing the dose of the second GKRS would be helpful, as would moving the target to not overlap with the previous target, so that a previously treated nerve is not exposed to a high dose of radiation. ${ }^{54}$

\section{GKRS policy: dose and target}

When GKRS was first used for TN, Leksell ${ }^{3}$ targeted the Gasserian ganglion. After that, Lindquist, et al. ${ }^{4}$ reported the results of GKRS targeting the Gasserian ganglion in 1991 and then stated the results of treatment of the trigeminal REZ, where peripheral myelination with Schwann cells transits to central myelination with oligodendrocytes. Rand, et al. ${ }^{57}$ reported the results of the GKRS targeting the retrogasserian area, anterior to REZ, in 1993. Since then, both the REZ and retrogasserian area have been used to treat TN with GKRS (Fig. 6). 
Our study 2019

Young, et al. (1998)

Maesawa, et al. (2001) $)^{35}$

Pollock, et al. (2002) ${ }^{42}$

Petit, et al. $(2003)^{67}$

Sheehan, et al. $(2005)^{68}$

Urgosik, et al. (2005) ${ }^{38}$

Longhi, et al. (2007) 40

Fountas, et al. $(2007)^{48}$

Kondziolka, et al. $(2010)^{5}$

Hayashi, et al. $(2011)^{69}$

Marshall, et al. (2012) $)^{44}$

Young, et al. $(2013)^{47}$

Lucas, et al. (2014) ${ }^{70}$

Régis, et al. (2016) ${ }^{6}$

Taich, et al. $(2016)^{49}$

Martínez Moreno, et al. (2016)

Zhao, et al. (2018) $)^{50}$

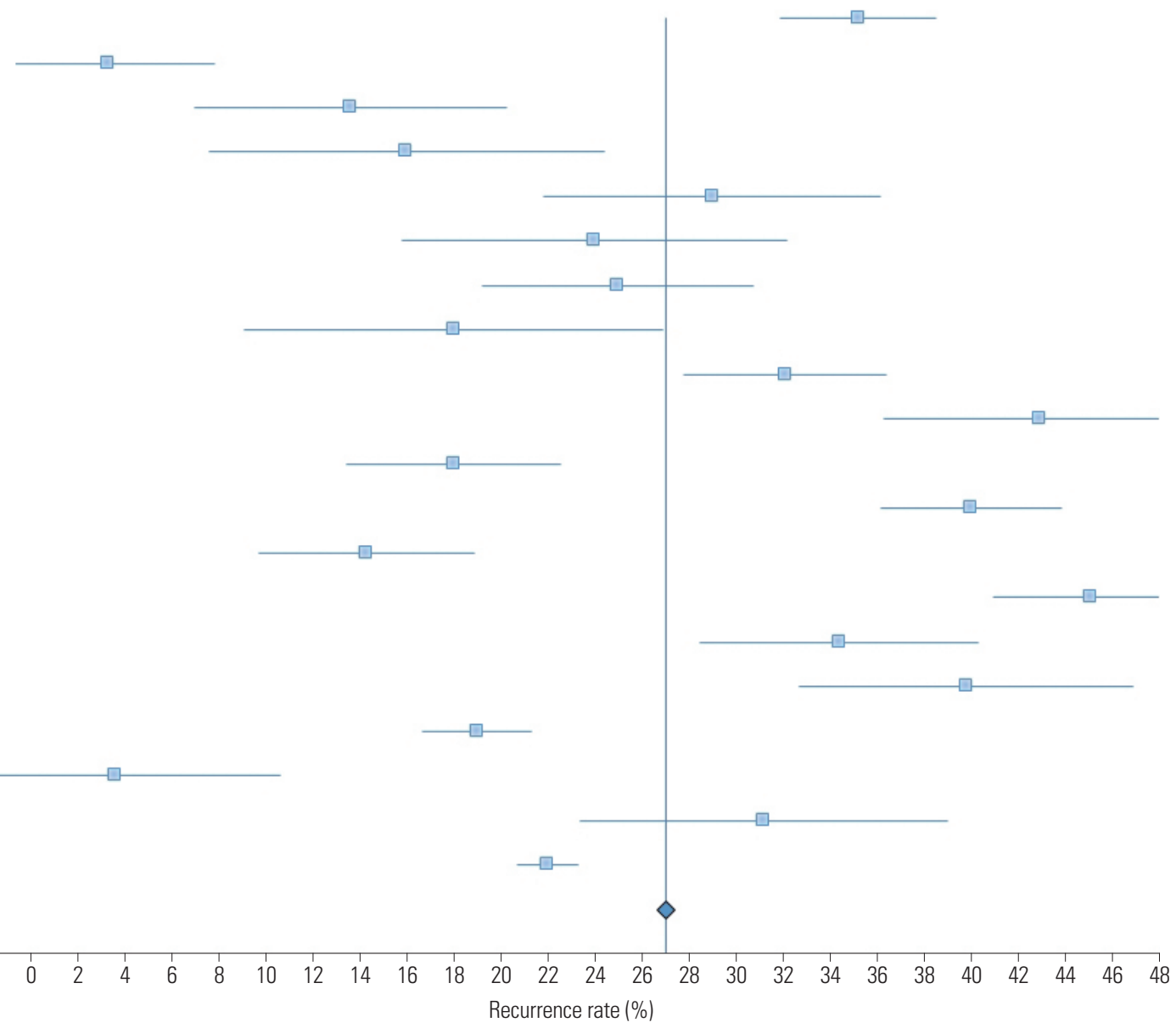

Fig. 5. Forest plot of complication rates in 19 studies. Confidence intervals were calculated at a confidence level of $95 \%$ for a single proportion.

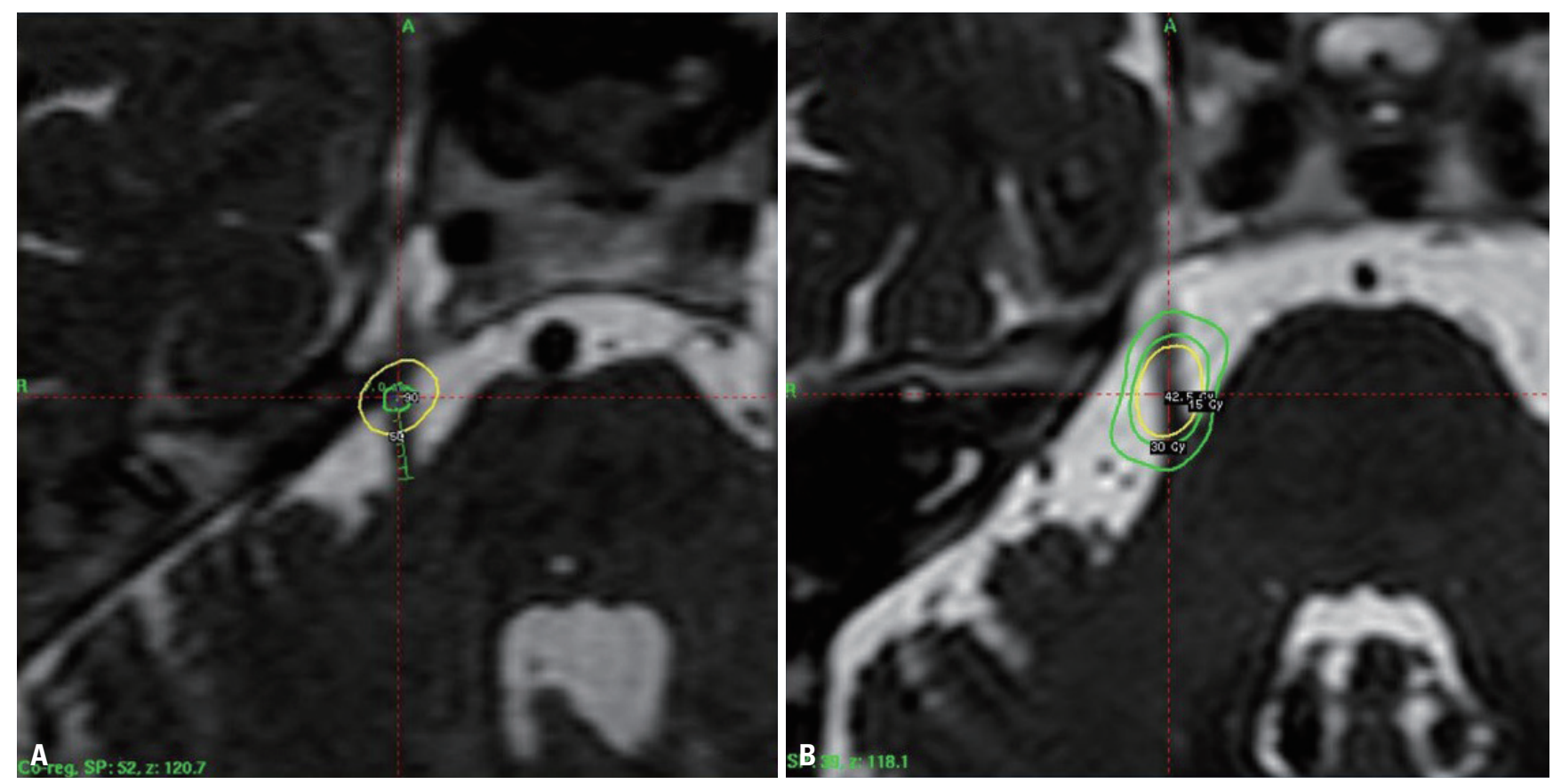

Fig. 6. Targets used in Gamma Knife radiosurgery for trigeminal neuralgia. Retrogasserian area (A) and trigeminal root entry zone (B). 
There is still controversy regarding which target is better. The major difference between the targets is the dose received by the REZ and the brainstem. However, the effect and complications related to the target and the dose are not established. Several studies have compared the complications and effects between anterior and posterior targets. ${ }^{58-60}$ They reported that an anterior target has lower complications than a posterior target, showing similar or better pain relief. However, since there is a difference between doses among studies and targets and the appropriate dose has not yet been established for the target, it is difficult to directly determine which target is better.

Determination of the treatment dose may vary according to the target. However, studies have shown that a dose of $70 \mathrm{~Gy}$ failed to control pain in $100 \%$ and that radiation below $70 \mathrm{~Gy}$ had little effect on the structure of the trigeminal nerve. ${ }^{61,62} \mathrm{~A}$ radiation dose of more than 80 Gy causes partial degeneration with loss of axons and demyelination, which is the mechanism of pain relief in GKRS. ${ }^{62}$ Therefore, GKRS with 80 Gy or higher is usually performed. In addition, many studies have shown that higher doses lead to greater pain control. ${ }^{63-65}$ However, a high dose of more than 90 Gy is related to a higher complication rate with similar pain control effects; hence, they are not usually used. ${ }^{5,6}$ Recently, a dose between 80 and 90 Gy is generally used, with modification depending the circumstances.

\section{CONCLUSION}

GKRS has been used for TN for a long time with low complication rates and high success rates. Over time, technical refinements have improved its safety and efficacy. GKRS is being increasingly used as a primary intervention for $\mathrm{TN}$ for patients who cannot undergo surgery due to medical comorbidities and age or for those who refuse invasive therapy. To further increase safety and efficiency, discussions are underway on the treatment policy to be applied. In the future, advances in imaging modalities and in GKRS technique, as well as accumulation of long-term results and experience will yield better results of GRKS for TN.

\section{AUTHOR CONTRIBUTIONS}

Conceptualization: Jin Woo Chang. Data curation: So Hee Park. Formal analysis: So Hee Park. Methodology: Jin Woo Chang and So Hee Park. Project administration: Jin Woo Chang. Resources: Jin Woo Chang and So Hee Park. Software: So Hee Park. Supervision: Jin Woo Chang. Validation: Jin Woo Chang. Visualization: So Hee Park. Writing — original draft: So Hee Park. Writing_review \& editing: Jin Woo Chang and So Hee Park. Approval of final manuscript: all authors.

\section{ORCID iDs}

So Hee Park https://orcid.org/0000-0003-0114-8587 Jin Woo Chang https://orcid.org/0000-0002-2717-0101

\section{REFERENCES}

1. Headache Classification Committee of the International Headache Society (IHS). The international classification of headache disorders, 3rd edition (beta version). Cephalalgia 2013;33:629-808.

2. McMillan R. Trigeminal Neuralgia-a debilitating facial pain. Reviews in Pain 2011;5:26-34.

3. Leksell L. The stereotactic method and radiosurgery of the brain. Acta Chir Scand 1951;102:316-9.

4. Lindquist C, Kihlström L, Hellstrand E. Functional neurosurgery-a future for the gamma knife? Stereotact Funct Neurosurg 1991; 57:72-81.

5. Kondziolka D, Zorro O, Lobato-Polo J, Kano H, Flannery TJ, Flickinger JC, et al. Gamma Knife stereotactic radiosurgery for idiopathic trigeminal neuralgia. J Neurosurg 2010;112:758-65.

6. Régis J, Tuleasca C, Resseguier N, Carron R, Donnet A, Gaudart J, et al. Long-term safety and efficacy of Gamma Knife surgery in classical trigeminal neuralgia: a 497-patient historical cohort study. J Neurosurg 2016;124:1079-87.

7. Romanelli P, Heit G, Chang SD, Martin D, Pham C, Adler J. Cyberknife radiosurgery for trigeminal neuralgia. Stereotact Funct Neurosurg 2003;81:105-9.

8. Smith ZA, Gorgulho AA, Bezrukiy N, McArthur D, Agazaryan N, Selch MT, et al. Dedicated linear accelerator radiosurgery for trigeminal neuralgia: a single-center experience in 179 patients with varied dose prescriptions and treatment plans. Int J Radiat Oncol Biol Phys 2011;81:225-31.

9. Costa GMF, Leite CMdA. Trigeminal neuralgia: peripheral and central mechanisms. Rev Dor 2015;16:297-301.

10. Yadav YR, Nishtha Y, Sonjjay P, Vijay P, Shailendra R, Yatin K. Trigeminal neuralgia. Asian J Neurosurg 2017;12:585-97.

11. Kumar S, Rastogi S, Kumar S, Mahendra P, Bansal M, Chandra L. Pain in trigeminal neuralgia: neurophysiology and measurement: a comprehensive review. J Med Life 2013;6:383-8.

12. Love S, Coakham HB. Trigeminal neuralgia: pathology and pathogenesis. Brain 2001;124:2347-60.

13. Marinković S, Gibo H, Todorović V, Antić B, Kovacević D, Milisavljević $\mathrm{M}$, et al. Ultrastructure and immunohistochemistry of the trigeminal peripheral myelinated axons in patients with neuralgia. Clin Neurol Neurosurg 2009;111:795-800.

14. Burchiel KJ. A new classification for facial pain. Neurosurgery 2003;53:1164-6.

15. Wiffen PJ, McQuay HJ, Moore RA. Carbamazepine for acute and chronic pain. Cochrane Database Syst Re 2005:CD005451.

16. Montano N, Conforti G, Di Bonaventura R, Meglio M, Fernandez E, Papacci F. Advances in diagnosis and treatment of trigeminal neuralgia. Ther Clin Risk Manag 2015;11:289-99.

17. Cruccu G, Gronseth G, Alksne J, Argoff C, Brainin M, Burchiel K, et al. AAN-EFNS guidelines on trigeminal neuralgia management. Eur J Neurol 2008;15:1013-28.

18. Barker FG, Jannetta PJ, Bissonette DJ, Larkins MV, Jho HD. The long-term outcome of microvascular decompression for trigeminal neuralgia. N Engl J Med 1996;334:1077-84.

19. Burchiel KJ, Clarke H, Haglund M, Loeser JD. Long-term efficacy of microvascular decompression in trigeminal neuralgia. J Neurosurg 1988;69:35-8.

20. Sekula RF Jr, Frederickson AM, Jannetta PJ, Quigley MR, Aziz KM, Arnone GD. Microvascular decompression for elderly patients with trigeminal neuralgia: a prospective study and systematic review with meta-analysis. J Neurosurg 2011;114:172-9.

21. Yang DB, Wang ZM, Jiang DY, Chen HC. The efficacy and safety of microvascular decompression for idiopathic trigeminal neuralgia 
in patients older than 65 years. J Craniofac Surg 2014;25:1393-6.

22. Parmar M, Sharma N, Modgill V, Naidu P. Comparative evaluation of surgical procedures for trigeminal neuralgia. J Maxillofac Oral Surg 2013;12:400-9.

23. Park SS, Lee MK, Kim JW, Jung JY, Kim IS, Ghang CG. Percutaneous balloon compression of trigeminal ganglion for the treatment of idiopathic trigeminal neuralgia: experience in 50 patients. J Korean Neurosurg Soc 2008;43:186-9.

24. Asplund P, Blomstedt P, Bergenheim AT. Percutaneous balloon compression vs percutaneous retrogasserian glycerol rhizotomy for the primary treatment of trigeminal neuralgia. Neurosurgery 2016;78:421-8.

25. Pollock BE. Percutaneous retrogasserian glycerol rhizotomy for patients with idiopathic trigeminal neuralgia: a prospective analysis of factors related to pain relief. J Neurosurg 2005;102:223-8.

26. Yoon KB, Wiles JR, Miles JB, Nurmikko TJ. Long-term outcome of percutaneous thermocoagulation for trigeminal neuralgia. Anaesthesia 1999;54:803-8.

27. Wu CY, Meng FG, Xu SJ, Liu YG, Wang HW. Selective percutaneous radiofrequency thermocoagulation in the treatment of trigeminal neuralgia: report on 1860 cases. Chin Med J (Engl) 2004;117: 467-70.

28. Fouad W. Management of trigeminal neuralgia by radiofrequency thermocoagulation. Alex J Med 2011;47:79-86.

29. Tuleasca C, Régis J, Sahgal A, De Salles A, Hayashi M, Ma L, et al. Stereotactic radiosurgery for trigeminal neuralgia: a systematic review: International Stereotactic Radiosurgery Society Practice Guidelines. J Neurosurg 2018;130:733-57.

30. Tang YZ, Wu BS, Yang LQ, Yue JN, He LL, Li N, et al. The longterm effective rate of different branches of idiopathic trigeminal neuralgia after single radiofrequency thermocoagulation: a cohort study. Medicine (Baltimore) 2015;94:e1994.

31. Keep MF, DeMare PA, Ashby LS. Gamma knife surgery for refractory postherpetic trigeminal neuralgia: targeting in one session both the retrogasserian trigeminal nerve and the centromedian nucleus of the thalamus. J Neurosurg 2005;102 Suppl:276-82.

32. Tuleasca C, Carron R, Resseguier N, Donnet A, Roussel P, Gaudart J, et al. Multiple sclerosis-related trigeminal neuralgia: a prospective series of 43 patients treated with gamma knife surgery with more than one year of follow-up. Stereotact Funct Neurosurg 2014; 92:203-10.

33. Schwarz W, Fox JM. Effects of monochromatic X-radiation on the membrane of nodes of Ranvier under voltage and current clamp conditions. Experientia 1979;35:1200-1.

34. Szeifert GT, Salmon I, Lorenzoni J, Massager N, Levivier M. Pathological findings following trigeminal neuralgia radiosurgery. Prog Neurol Surg 2007;20:244-8.

35. Maesawa S, Salame C, Flickinger JC, Pirris S, Kondziolka D, Lunsford LD. Clinical outcomes after stereotactic radiosurgery for idiopathic trigeminal neuralgia. J Neurosurg 2001;94:14-20.

36. Gronseth G, Cruccu G, Alksne J, Argoff C, Brainin M, Burchiel K, et al. Practice parameter: the diagnostic evaluation and treatment of trigeminal neuralgia (an evidence-based review): report of the Quality Standards Subcommittee of the American Academy of Neurology and the European Federation of Neurological Societies. Neurology 2008;71:1183-90.

37. Little AS, Shetter AG, Shetter ME, Bay C, Rogers CL. Long-term pain response and quality of life in patients with typical trigeminal neuralgia treated with gamma knife stereotactic radiosurgery. Neurosurgery 2008;63:915-24.

38. Urgosik D, Liscak R, Novotny J Jr, Vymazal J, Vladyka V. Treatment of essential trigeminal neuralgia with gamma knife surgery. J Neurosurg 2005;102:29-33.
39. Rogers CL, Shetter AG, Fiedler JA, Smith KA, Han PP, Speiser BL. Gamma knife radiosurgery for trigeminal neuralgia: the initial experience of The Barrow Neurological Institute. Int J Radiat Oncol Biol Phys 2000;47:1013-9.

40. Longhi M, Rizzo P, Nicolato A, Foroni R, Reggio M, Gerosa M. Gamma knife radiosurgery for trigeminal neuralgia: results and potentially predictive parameters--part I: idiopathic trigeminal neuralgia. Neurosurgery 2007;61:1254-61.

41. Guo S, Chao ST, Reuther AM, Barnett GH, Suh JH. Review of the treatment of trigeminal neuralgia with gamma knife radiosurgery. Stereotact Funct Neurosurg 2008;86:135-46.

42. Pollock BE, Phuong LK, Gorman DA, Foote RL, Stafford SL. Stereotactic radiosurgery for idiopathic trigeminal neuralgia. J Neurosurg 2002;97:347-53.

43. Maher CO, Pollock BE. Radiation induced vascular injury after stereotactic radiosurgery for trigeminal neuralgia: case report. Surg Neurol 2000;54:189-93.

44. Marshall K, Chan MD, McCoy TP, Aubuchon AC, Bourland JD, McMullen KP, et al. Predictive variables for the successful treatment of trigeminal neuralgia with gamma knife radiosurgery. Neurosurgery 2012;70:566-73.

45. Tang X, Wu H, Wang B, Zhang N, Dong Y, Ding J, et al. A new classification and clinical results of Gamma Knife radiosurgery for cavernous sinus hemangiomas: a report of 53 cases. Acta Neurochir (Wien) 2015;157:961-9.

46. McNatt SA, Yu C, Giannotta SL, Zee C-S, Zelman V, Apuzzo ML, et al. Gamma knife radiosurgery for trigeminal neuralgia. Neurosurgery 2005;56:1295-303.

47. Young B, Shivazad A, Kryscio RJ, St Clair W, Bush HM. Long-term outcome of high-dose $\gamma$ knife surgery in treatment of trigeminal neuralgia. J Neurosurg 2013;119:1166-75.

48. Fountas KN, Smith JR, Lee GP, Jenkins PD, Cantrell RR, Sheils WC. Gamma Knife stereotactic radiosurgical treatment of idiopathic trigeminal neuralgia: long-term outcome and complications. Neurosurg Focus 2007;23:E8.

49. Taich ZJ, Goetsch SJ, Monaco E, Carter BS, Ott K, Alksne JF, et al. Stereotactic radiosurgery treatment of trigeminal neuralgia: clinical outcomes and prognostic factors. World Neurosurg 2016;90: 604-12.e11.

50. Zhao H, Shen Y, Yao D, Xiong N, Abdelmaksoud A, Wang H. Outcomes of two-isocenter gamma knife radiosurgery for patients with typical trigeminal neuralgia: pain response and quality of life. World Neurosurg 2018;109:e531-8.

51. Nicol B, Regine WF, Courtney C, Meigooni A, Sanders M, Young B. Gamma knife radiosurgery using $90 \mathrm{~Gy}$ for trigeminal neuralgia. J Neurosurg 2000;93:152-4.

52. Massager N, Nissim O, Murata N, Devriendt D, Desmedt F, Vanderlinden B, et al. Effect of beam channel plugging on the outcome of gamma knife radiosurgery for trigeminal neuralgia. Int J Radiat Oncol Biol Phys 2006;65:1200-5.

53. Pollock BE, Foote RL, Stafford SL, Link MJ, Gorman DA, Schomberg PJ. Results of repeated gamma knife radiosurgery for medically unresponsive trigeminal neuralgia. J Neurosurg 2000;93:162-4.

54. Hasegawa T, Kondziolka D, Spiro R, Flickinger JC, Lunsford LD. Repeat radiosurgery for refractory trigeminal neuralgia. Neurosurgery 2002;50:494-500.

55. Pollock BE, Foote RL, Link MJ, Stafford SL, Brown PD, Schomberg PJ. Repeat radiosurgery for idiopathic trigeminal neuralgia. Int J Radiat Oncol Biol Phys 2005;61:192-5.

56. Aubuchon AC, Chan MD, Lovato JF, Balamucki CJ, Ellis TL, Tatter $\mathrm{SB}$, et al. Repeat gamma knife radiosurgery for trigeminal neuralgia. Int J Radiat Oncol Biol Phys 2011;81:1059-65.

57. Rand RW, Jacques DB, Melbye RW, Copcutt BG, Levenick MN, 
Fisher MR. Leksell Gamma Knife treatment of tic douloureux. Stereotact Funct Neurosurg 1993;61:93-102.

58. Xu Z, Schlesinger D, Moldovan K, Przybylowski C, Sun X, Lee CC, et al. Impact of target location on the response of trigeminal neuralgia to stereotactic radiosurgery. J Neurosurg 2014;120:716-24.

59. Matsuda S, Serizawa T, Nagano O, Ono J. Comparison of the results of 2 targeting methods in Gamma Knife surgery for trigeminal neuralgia. J Neurosurg 2008;109:185-9.

60. Park SH, Hwang SK, Kang DH, Park J, Hwang JH, Sung JK. The retrogasserian zone versus dorsal root entry zone: comparison of two targeting techniques of gamma knife radiosurgery for trigeminal neuralgia. Acta Neurochir (Wien) 2010;152:1165-70.

61. Shaya M, Jawahar A, Caldito G, Sin A, Willis BK, Nanda A. Gamma knife radiosurgery for trigeminal neuralgia: a study of predictors of success, efficacy, safety, and outcome at LSUHSC. Surg Neurol 2004;61:529-34.

62. Zhao ZF, Yang LZ, Jiang CL, Zheng YR, Zhang JW. Gamma Knife irradiation-induced histopathological changes in the trigeminal nerves of rhesus monkeys. J Neurosurg 2010;113:39-44.

63. Shrivastava A, Mohammed N, Hung YC, Xu Z, Schlesinger D, Heinrichs $\mathrm{T}$, et al. Impact of integral dose on the maintenance of pain relief in patients with idiopathic trigeminal neuralgia treated with upfront Gamma knife radiosurgery. World Neurosurg 2019;129: e375-80.

64. Morbidini-Gaffney S, Chung CT, Alpert TE, Newman N, Hahn SS, Shah H, et al. Doses greater than 85 Gy and two isocenters in Gamma Knife surgery for trigeminal neuralgia: updated results. J Neurosurg 2006;105:107-11.

65. Kim YH, Kim DG, Kim JW, Kim YH, Han JH, Chung HT, et al. Is it effective to raise the irradiation dose from 80 to 85 Gy in gamma knife radiosurgery for trigeminal neuralgia? Stereotact Funct Neurosurg 2010;88:169-76.
66. Young RF, Vermulen S, Posewitz A. Gamma knife radiosurgery for the treatment of trigeminal neuralgia. Stereotact Funct Neurosurg 1998;70 Suppl 1:192-9.

67. Petit JH, Herman JM, Nagda S, DiBiase SJ, Chin LS. Radiosurgical treatment of trigeminal neuralgia: evaluating quality of life and treatment outcomes. Int J Radiat Oncol Biol Phys 2003;56:1147-53.

68. Sheehan J, Pan HC, Stroila M, Steiner L. Gamma knife surgery for trigeminal neuralgia: outcomes and prognostic factors. J Neurosurg 2005;102:434-41.

69. Hayashi M, Chernov M, Tamura N, Taira T, Izawa M, Yomo S, et al. Stereotactic radiosurgery of essential trigeminal neuralgia using Leksell Gamma Knife model C with automatic positioning system: technical nuances and evaluation of outcome in 130 patients with at least 2 years follow-up after treatment. Neurosurg Rev 2011;34: 497.

70. Lucas JT Jr, Nida AM, Isom S, Marshall K, Bourland JD, Laxton AW, et al. Predictive nomogram for the durability of pain relief from gamma knife radiation surgery in the treatment of trigeminal neuralgia. Int J Radiat Oncol Biol Phys 2014;89:120-6.

71. Martínez Moreno NE, Gutiérrez-Sárraga J, Rey-Portolés G, Jiménez-Huete A, Martínez Álvarez R. Long-term outcomes in the treatment of classical trigeminal neuralgia by Gamma Knife radiosurgery: a retrospective study in patients with minimum 2-year followup. Neurosurgery 2016;79:879-88.

72. Gagliardi F, Spina A, Bailo M, Boari N, Cavalli A, Franzin A, et al. Effectiveness of Gamma Knife Radiosurgery in improving psychophysical performance and patient's quality of life in idiopathic trigeminal neuralgia. World Neurosurg 2018;110:e776-85.

73. Lee CC, Chen CJ, Chong ST, Hung SC, Yang HC, Lin CJ, et al. Early stereotactic radiosurgery for medically refractory trigeminal neuralgia. World Neurosurg 2018;112:e569-75. 